\title{
COMMENT
}

\section{On the other side of the waiting room}

\author{
B C RAO'
}

'General practitioner, 847 Second Cross, Seventh Main, HAL 2nd Stage, Bangalore 560008 INDIA e-mail: badakere.rao@gmail.com

The writer has painted a worst-case scenario (1) based on her visits and observations. On the other hand, I have observed the practices of doctors who are members of a local family physicians' association, who have, over the years, tried to provide the best to their patients. What I am going to write is therefore the best-case scenario. The truth perhaps lies somewhere in between.

In the West the number of chronic cases is larger and the number of acute cases is fewer, and the doctor there has to see fewer patients. In India, the numbers are large and acute cases constitute a greater percentage of patients. Any appointment system in such a scenario will not work.

The time allotted to a patient in some of the good clinical practices that I know of is, on average, 10 minutes in an 8-10 hour working day. The average waiting time in most practices is about an hour, and even in these clinics a very ill patient will be seen out of turn. In some practices, such as mine, the waiting time is minimal because the number of patients I see is small. I have not seen any patient with "worry writ large" on their faces, as the writer has described. The patients are sick and so, of course, they will not be in the best of spirits. Any worry they may feel is because of the sickness and not because of the prospect of confronting the doctor, who they usually know well.

Contrast this with what I know of practices in the West. It is almost impossible to get access to any doctor in a hurry. Even acute cases cannot get an appointment during the scheduled hours and have to seek help in the emergency room, where the patient is likely to be seen by a doctor who does not know her/ him. Unnecessary investigations and procedures become a distinct possibility in such cases. Avoidable interventions are not uncommon. For example, one of my patients has a lipoma, which I had told her does not need surgery. Her USbased doctor strongly advised her to get it removed. She was so scared that she called to ask me what she should do. Such phone and e-mail consultations are also not uncommon in India.

A waiting room gets crowded because of the sheer numbers and the expense involved in having larger clinics. Most patients cannot afford to pay the fee we think we deserve, and a sizeable percentage of the patients are treated free of cost. Many doctors I know have made changes in their practice and, to some extent, have resolved this problem by doing things like running special clinics at designated times and issuing tokens. I do agree that problems exist, not because of an uncaring attitude but because of socio-economic considerations. Written records are indeed possible and some of us do maintain meticulous records despite the time constraints. There is no fear of the taxman because he knows that a general practitioner's income is not worth bothering about.

While it is inexcusable for a psychiatrist to spend ten minutes with a patient, I think the writer should spend some time in one of our clinics and see the levels of psychological comfort among the waiting patients. I agree that a pleasant and spacious waiting area is required and some of us have provided this, though it may be below the western standard. This does not make our patients less happy than their western counterparts. It is uncharitable to generalise that we don't treat our patients with courtesy and consideration. There may be exceptions, but then, that would be true also for the West.

We do have special clinics at fixed times to see chronic cases, for follow-up visits, and for new cases. But these are never six months into the future. The reasons are many. Even after having this system in place for over 10 years I am not happy with it because many of the appointments are not kept and I end up wasting valuable time. In a small study, I found that appointments are usually not kept because of unexpected situations, terrible traffic, because the patient feels well, or because she/ he forgot about the appointment.

I agree with the writer that preventive care is still not the norm in India. Most patients reason that if they are well, they need not spend money. Most of them pay out of their pocket and many with limited incomes must find ways of limiting costs.

Coming to the matter of status, yes, we have treated the doctors who are patients out of turn and continue to do so. However, I always ask for the permission of the waiting patients if I have to see another patient out of turn for any reason.

The relationship with our patients, built over many years, is not disturbed if we take a holiday. We may be apprehensive when we get back, but usually the patients do visit again. I know this from my own as well as other doctors' experiences.

I agree that the "executive" check-up is a farce and tests are best left to the physician, who will order them after a need-based analysis. Costs of care can never be standardised in the Indian context. In many practices, fees are based on the patient's 
ability to pay, which can often be difficult to determine. A consultant's charges are different from a family physician's, though this is not always true.

There is undoubtedly scope for improvement and many practices have changed in ways that benefit both doctor and patient. The quality of care in the practices that I know of is quite good considering the constraints under which we work and live. Most of us are happy not because we make large amounts of money but because of the immense professional satisfaction we derive from our family medical practice.

What, then, is the "shabby" treatment of our patients that the writer is contrasting with the apparently "excellent" treatment that patients get in the West?

Reference

1. Mamdani M.Waiting for the doctor... Indian J Med Ethics 2007; 4:126-7.

\section{INDIAN JOURNAL OF MEDICAL ETHICS}

The Indian Journal of Medical Ethics carries original articles, reports, comments, case studies and other material on a range of issues related to health care ethics in developing countries, with special reference to India.

Some of these:

- Corruption among medical professionals $\bullet$ Ethics education during medical college $\bullet$ Issues in high-technology medicine - Problems of research among poor populations $\bullet$ Contraceptive research and population policies.

In order to engage people in debates on health and medical practice, IJME encourages comments from all points of view.

Some debates in recent issues:

- Is it right to perform pre-implantational genetic diagnosis for sex selection? • Is ECT without anaesthesia unethical? • May doctors refuse to treat people with HIV? • Should doctors advertise?

IJME is owned and published by the Forum for Medical Ethics Society, a not-for-profit, voluntary organisation in Mumbai, India. The FMES was born out of an effort by a group of concerned doctors to focus attention on the need for ethical norms and practices in health care.

\section{Subscribe to IJME and participate in the debate.}

\section{If you're already a subscriber, why don't you gift a subscription to a friend?}

Demand drafts /cheques should be in the name of 'Indian Journal of Medical Ethics'.

- Please add Rs 30 for out-station cheques (US\$2 for international subscriptions).

- Personal subscriptions paid from personal funds are available at $\mathbf{5 0} \%$ discounted rates.

$\downarrow$ Subscribers from other SAARC countries (Bangladesh, Bhutan, Maldives, Nepal, Pakistan and Sri Lanka) please pay the Indian rates adding Rs 100 per year extra for postage.

$\downarrow$ Special one-year subscriptions for Rs $\mathbf{1 5 0}$ are available to students in India.

\section{Subscription rates}

\begin{tabular}{|l|c|c|c|c|}
\hline & \multicolumn{2}{|c|}{ Indian } & \multicolumn{2}{c|}{ International } \\
\hline & Individual & Institutional & Individual & Institutional \\
\hline One year & Rs 250 & Rs 500 & US\$20 & US\$40 \\
\hline Two years & Rs 450 & Rs 900 & US\$35 & US\$70 \\
\hline Five years & Rs 1,000 & Rs 2,000 & US\$80 & US\$160 \\
\hline Life & Rs 10,000 & Rs 20,000 & & US\$1,600 \\
\hline
\end{tabular}

\Please send your subscriptions and subscription queries to: Indian Journal of Medical Ethics, C/o CSER, Candelar, 4th Floor, 26 St John Baptist Road, Bandra (W), Mumbai 400050 INDIA e-mail: fme@vsnl.net 